\title{
WATER BALANCE OF THE RESPIRATORY TRACT \\ DURING VENTILATION WITH A GAS MIXTURE SATURATED AT BODY TEMPERATURE
}

\author{
RAYNALD DÉRY*, M.D., F.R.C.P.(c)
}

IT IS A WELL KNOWN FACT that every man breathing ambient air, either through his nose or mouth, undergoes a respiratory water deficit. This negative balance results from the expired air leaving the lungs saturated with water vapour at a temperature below body temperature, whereas the inspired gases, except under unusual conditions, are both dryer and colder. On an average, the water loss from the respiratory tract amounts to $300 \mathrm{ml}$ per day, equivalent to a gross loss of 10 per cent on the negative side of the circadian water transactions for the whole body. This is the normal situation as it prevails in human physiology. ${ }^{1-5}$

A more negative water balance is hardly conceivable. The local thermodynamic processes which automatically regulate the heat and moisture exchanges at the air mucosa interface can achieve a rapid acclimatization to a wide range of adverse conditions within a few breaths. When dry and/or cold air is being inspired, water conservation is promoted by two efficient mechanisms. These are increased condensation of expired moisture on the mucous membranes and a downward shift of the isothermic saturation boundary in the respiratory tract. This results in a larger area of the mucous membranes being reset at a higher level of efficiency in dealing with water exchanges of evaporation and condensation. ${ }^{6}$

A positive water balance, meaning that larger amounts of water vapour actually enter the respiratory tract than leave it during expiration, probably approaches the limit of physical tolerance. Continuous exposure to a saturated ambient atmosphere above $37^{\circ} \mathrm{C}$ is a thermo-hydric stress which, in the absence of acclimatization, is hard to endure, if not intolerable for the human body as a whole. ${ }^{7-8}$ However, with modern advances in respirology, the administration of cold or heated aerosols has eased the way to a positive respiratory water budget, without submitting the whole body to a distressing thermal environment.

Somewhere between a normal water loss and an artificial water gain stands isothermic saturation. Ideally, this consists of the administration of inspired gases saturated with water vapour at body temperature. This work describes our results in an investigation of this particular aspect of pulmonary physiology.

\section{METHODS}

The measurement of the respiratory water balance in the patient during general anaesthesia is associated with two definite, although remote, hazards. The first

*Department of Anaesthesia and Resuscitation, L'Hôtel-Dieu de Québec and Laval University.

This work was supported by the Grant No. MA 2968, provided by the Medical Research Council.

Canad. Anaesth. Soc. J., vol. 20, no. 6, November 1973 


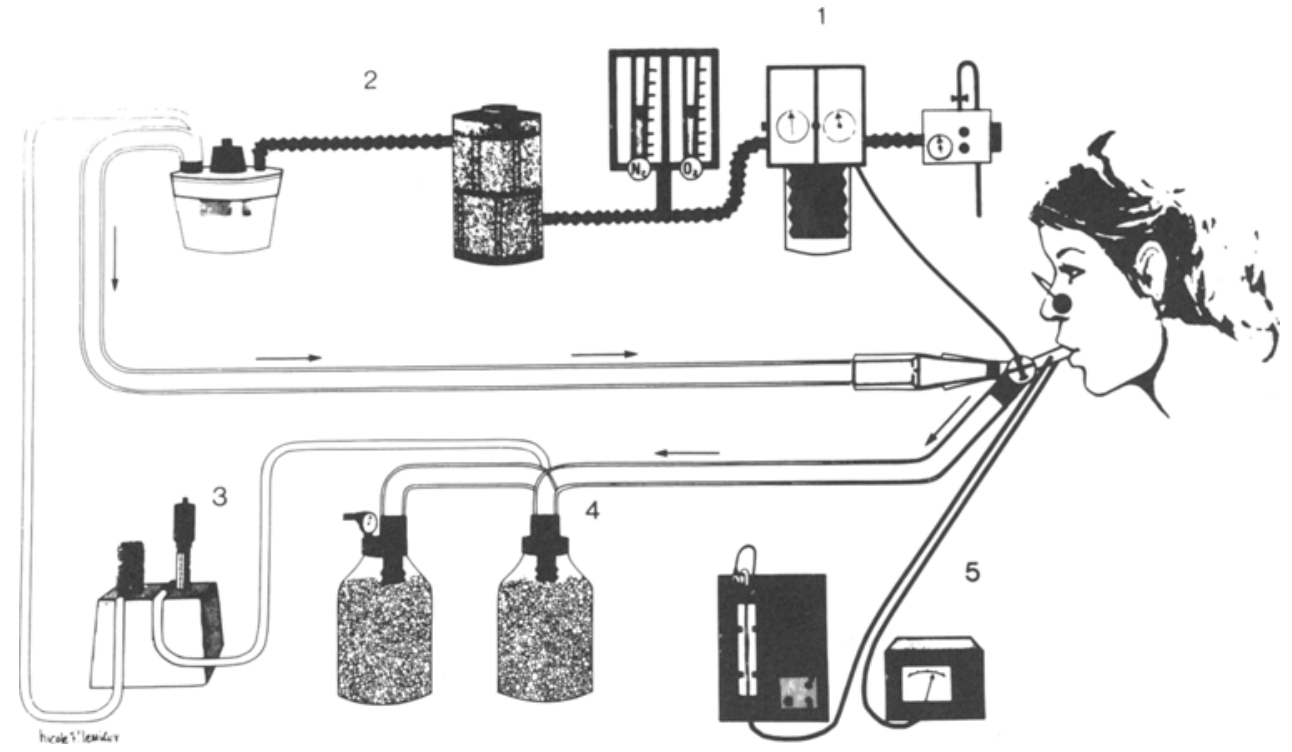

Figure 1. Scheme of the experimental system used to measure the water balance of the respiratory tract during ventilation with a gas mixture saturated at body temperature.

The main components are: 1-A constant volume ventilator, 2 - the humidifying unit, $3-$ the thermostatic bath and water circulation system, $4-$ the moisture absorbers, 5 -the monitors, thermometric and hygrometric.

is the necessity to use a heater on the inspiratory system delivering gases to the patient. This demands not only constant but very accurate monitoring of inspiratory gas temperature, to avoid burns to the respiratory mucosa. ${ }^{7}$ The second is the presence, on the expiratory limb of the system, of a moisture absorber. Anhydrous calcium chloride, although a very efficient lyophilic chemical, may release minute amounts of dust which, if inadvertently rebreathed, would prove tremendously corrosive to the respiratory tract.

For these reasons, our measurements were effected in the conscious volunteer, in the laboratory, with due attention to the hazards previously described.

Six experiments were conducted on the unpremedicated subject. The duration of each session had to be limited to one hour because of the discomfort experienced by the subject.

Figure 1 displays the experimental assembly adopted for this study. Its first component, intermittent positive pressure breathing, was provided by a Bird Mark 4-Mark 7 ventilator unit, delivering a steady tidal volume of one litre (BTPS) at a rate of 10 per minute. Dehydration of the concertina bag and of the tubings of the respirator was insured by previous flushing with desiccated oxygen for two hours. The same respirator was used for each experiment; this, along with the nonrebreathing technique, minimized the possibility of exogeneous water contamination. The inflowing gases delivered to the concertina bag and eventually to the humidifying system consisted of a mixture of 50 per cent oxygen and 50 per cent compressed air, both dehydrated. Their admission into the inspiratory system was through the debimeters of an Ohio Vernitrol anaesthesia apparatus; the accuracy of the latter was controlled both at the beginning and at the end of 
each experiment with a Wright anemometer, a Collin's expirometer and a Godart Pulmonet Spirometer.

The process for humidifying the inspired gas mixture was complicated by the evidence that the Bennett Cascade ${ }^{\circledR}$ Humidifier is not a perfect saturator; ${ }^{10}$ its efficiency varies with the peak flow of the gas crossing its baffles. This inefficiency was easily corrected by the addition before the Cascade humidifier, of a supplementary moisture provider, a giant size soda lime absorber. ${ }^{11}$ Thus, saturation of the gas mixture at $37^{\circ} \mathrm{C}$ could be obtained with precision for unlimited periods and without any variations in the conditions.

The prevention of water condensation inside both the inspiratory and the expiratory limbs of the system confronted us with a major problem. This was solved by insulating the length of the tubing and the valves with an external jacket of polyvinyl chloride tubing and membranes, through which water at $37^{\circ} \mathrm{C}$ was recirculated at high flow rates from a thermostatic bath. The experimental stability of the thermo-hydric properties of the respired gas mixture proved to be highly reliable under those conditions, as was demonstrated by repeated controls.

A perfect separation between the inspired and expired gas mixtures was of importance in this particular study and accordingly strict attention was paid to this matter. It being well understood that the rebreathing of any amount of expired air into the inspiratory system would introduce an error which would invalidate the results, ${ }^{12}$ we devised a unit consisting of two unidirectional, insulated valves. A Beaver non-rebreathing valve was connected, on the inspiratory limb, to a Bird two-way valve attached to the mouthpiece. Complete closure of the Bird valve during inspiration was ensured by the application, on the expiratory seat of the valve, of a pressure head of 60 pounds per square inch. In this way, no inspired air could by-pass the respiratory tract and eventually reach the expiratory limb of the system. During the expiratory phase, the Beaver valve prevented any contamination of the inspiratory limb by expired air. Unidirectionality of the system was controlled with an infra-red $\mathrm{CO}_{2}$ analyser.

The absorption of the expired moisture was effected by passing the outflowing gases through two anhydrous $\mathrm{CaCl}_{2}$ canisters, mounted in series, and filled with fresh, 4-8 mesh granules. Absorption was completed by the time the gases had passed through the first canister, which was shown by the absence of any weight gain in the second canister.

Monitoring before, during, and after each experiment included thermometric measurements of body temperature and of the thermal evolution of the gas mixture inside the mouthpiece. The relative humidity and moisture content of both the inspired and expired gas mixtures were measured with the modified Dew-point hygrometer. ${ }^{13}$ Finally, the difference between the input of water vapourized from the soda lime and the Cascade humidifier, and the output condensed in the $\mathrm{CaCl}_{2}$ absorbers was measured accurately with a Sartorious balance. Weighing was carried out under a stable atmospheric hood.

\section{Results}

First, brief mention will be made of the subjective discomfort experienced during the procedure. A sensation of warmth and, paradoxically, of dryness, was 


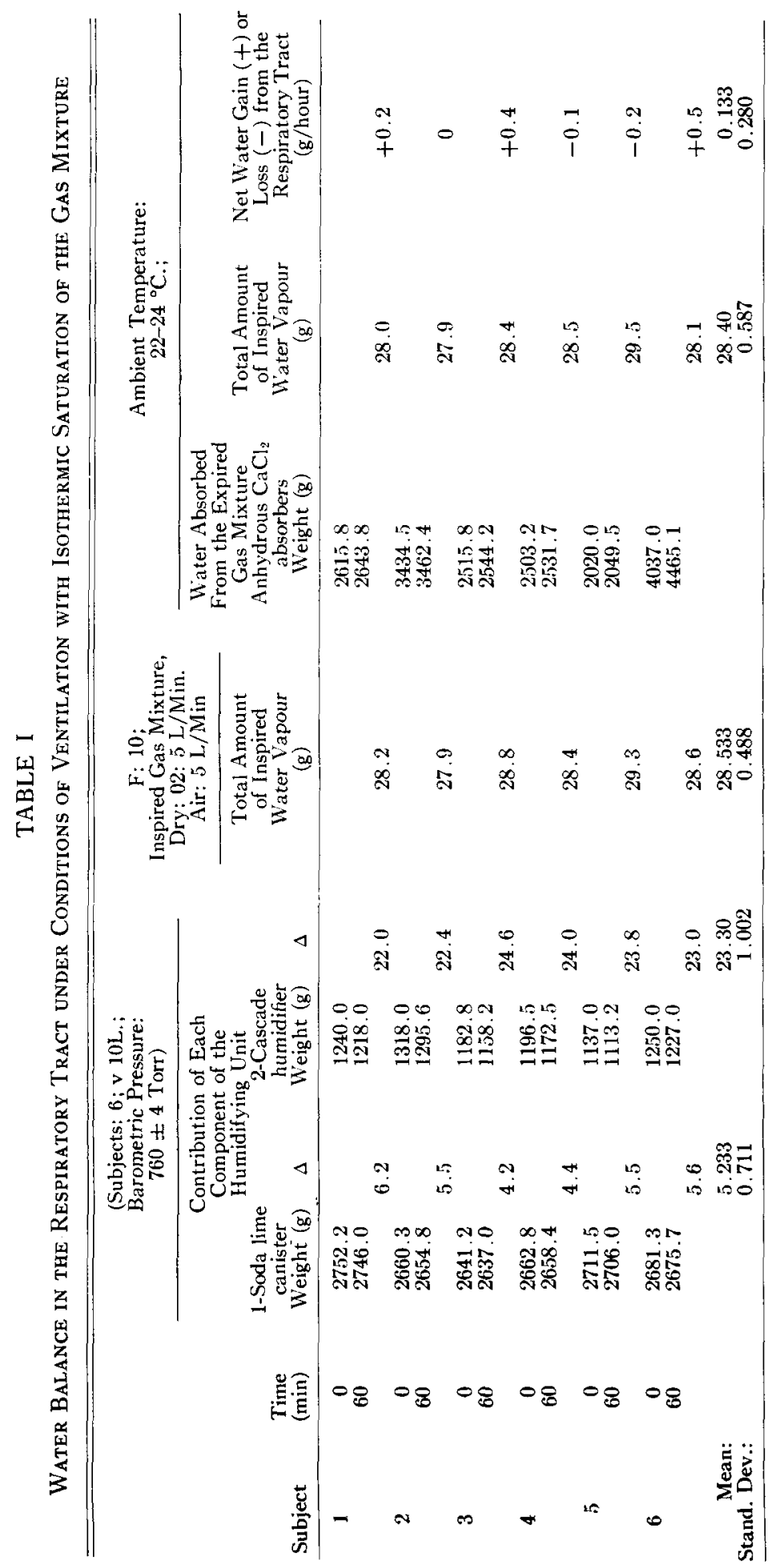


felt in the larynx and the trachea. Partial deafness was a constant feature, due to hypobarism within the middle ear and probably resulting from congestion of the Eustachian tubes and occlusion of their orifices in the nasopharynx. Temporary relief could be obtained by performing a Valsalva manoeuvre. More troublesome side effects occurred on three occasions following these experiments. There were two cases of acute otitis media, which recovered after two days of antibiotic treatment and one case of acute irritative tracheitis, with a dry cough and a burning sensation, which subsided after two days without any treatment.

As the chief aim of these measurements was the exact quantitative determination of the water budget of the respiratory tract under conditions of isothermic saturation, the pertinent data and the statistical analysis of the results are given in full in Table I. The main findings described in this table reach a single conclusion: every molecule of water administered under the conditions of isothermic saturation was rejected by the lungs and upper air passages, and was subsequently recovered by the water absorption unit.

This results in a zero water balance, not a single drop of water having been gained or lost by the respiratory tract with this technique.

\section{Discussion}

The results of these experiments require some amplification or qualification.

We were certainly frustrated when we noticed that the decreasing amount of water in the Cascade humidifier was completely out of proportion with the water volume we thought was being retained inside the respiratory tract. It might be very comforting for a physician to be left with the impression that he had actually administered over $20 \mathrm{gm}$ of water per hour to the lungs, and therefore to draw the gratifying conclusion that he had provided his patient with plenty of water to be used for growing a thicker dew-deposit all over the muco-ciliary apparatus in order to liquify mucus concretions and to minimize the overall evaporative load of the mucous membranes. But such premature speculations should be reevaluated in the light of our findings which indicate that, under conditions of isothermic saturation, a true thermo-hydric physiological by-pass occurs. The situation with which we have to be concerned is that the whole amount of water we tried to deposit in the air passages was completely recovered in the moisture absorber set on the expiratory limb of the system, as if it was bypassing the respiratory tract.

In the light of the understanding we have gathered from previous work in this particular field, we can attempt to explain what actually occurred in the respiratory tract under those circumstances and how it happened. The administration of a saturated gas mixture at body temperature raised the isothermic saturation boundary (I.S.B.) from its usual site, near the carina, all the way up to the mouth. Consequently, thermal gradients and Fickian gradients for $\mathrm{P}_{\mathrm{H}_{2} \mathrm{O}}$ no longer existed all along the airway; therefore, water and heat exchanges at the gas mucous membrane interface could no longer occur in both phases of the breathing cycle. A static situation had replaced a dynamic physiological pattern. 
This static situation is normally found below the isothermic saturation boundary, in the functional residual capacity and inside the bronchial divisions leading to it. ${ }^{6}$ At this site, the temperature of both the mucous membrane and the respiratory gases remain steady at body temperature, the latter being saturated with water vapour at the same temperature. Under such circumstances, a biophysical steady state can be conceived of, where no thermohydric fluxes can occur. It is also conceivable that a thin dew deposit is being constantly retained over the walls of the airways, because of the interplay of several forces, namely surface tension activity, Van der Waal's forces and loose, reversible bonding with the polyhydrates of mucus.

Above the isothermic saturation boundary there normally prevails a dynamic pattern of heat and moisture evolution along gradients for $\mathbf{P}_{\mathrm{H}_{2} \mathrm{O}}$ and joules. This mechanism which automatically regulates the climatic conditions in the upper air passages is necessary for the maintenance of an ideal environment for the respiratory mucosa against extreme variations of inspired air, as may occur during anaesthesia.

The existence of this self-regulating mechanism was demonstrated in retrospect after measurements of temperature at the surface of the nasal mucous membrane under different experimental conditions. The mucosal temperature two centimeters inside the opening of the nostril reads a steady $32^{\circ} \mathrm{C}$ when a subject breathes atmospheric air at a relative humidity of 45 per cent at $24^{\circ} \mathrm{C}$. It reads $28^{\circ} \mathrm{C}$ when dry oxygen is being breathed at the same temperature. Under more adverse conditions, like breathing air at subzero temperature, the temperature reading at the same site falls to $10-15^{\circ} \mathrm{C}$. In this situation, condensation of moisture over the nasal mucosa is so heavy that water droplets conglomerate, a well-known situation described as the running nose. These large water droplets obviously will not evaporate moisture as readily as would a thin multilayered dew deposit, because of the intrinsic stability afforded by both Van der Waal's forces and surface tension forces. This results in lack of humidity in plenty of water. The slow evaporation from these drops provides unusually cold and dry air to the naso-pharynx, the larynx and the trachea, leading to malfunction, irritation, decreased resistance to microorganisms and eventually to disease. It is therefore likely that the self-regulating thermo-hydric mechanism has limits. The question is, do aerosol therapy and water nebulization go beyond these limits? From the point of view of the mucosal cells, aerosol therapy looks like a heavy rain of water droplets. Whether or not this constitutes a healthier environment for a normal respiratory tract remains open to discussion, and will not be dealt with at this time.

The administration of a gas mixture saturated at a high temperature $\left(37^{\circ} \mathrm{C}\right.$ and over) is beyond the range of normal climatic conditions for breathing. This results in vasodilation, with congestion of the nasopharynx, the Eustachian tubes and openings, the larynx and the trachea, with possible dire effects, as experienced on three occasions in our study. Moreover, the density of the dew deposit over the mucosa of the upper airway may be very thin under these circumstances, resulting in poor muco-ciliary activity.

These findings, along with the interpretation we give to them, should not 
preclude the judicious addition of water to the inspired gas mixture, whenever deemed necessary. This is particularly true when oxygen is administered through a nasal catheter. The continuous flow of dry oxygen over an area of the mucous membrane causes the appearance of a dry spot where no moisture can condense during expiration. The low efficiency of the water vaporizers generally used to humidify oxygen administered through nasal catheters leads, in practice, to the same result. Within a short period of time, the subject complains of dryness of his nasopharynx and oropharynx; eventually, the physician will notice crust formations, mucosal damage and infection.

The administration of a moisturized gas mixture to patients with a tracheostomy is actually under review. Preliminary results from measurements of heat and moisture seem to indicate that the thermo-hydric self-regulating mechanism is probably efficient enough to cope with this situation where the upper air passages are being by-passed for short or prolonged periods of time. Our impression is that the interruption of the muco-ciliary apparatus, as caused by a cuff, by the local damage from the canula itself, and by epithelial metaplasia, plays an important part in the peculiar respiratory problems in these patients. In this view, the administration of moisture to patients with a tracheostomy should be interpreted as a treatment rather than as a supplementary measure to compensate for a failure of the thermo-hydric self-regulating mechanism of the air passages.

\section{Summary and Conclusion}

The water balance of the respiratory tract is actually a zero balance when air saturated with water vapour at body temperature is being inspired. A false impression of a net water gain by the airway may be created by correlating the water loss from the humidifier with the water gain by the respiratory tract.

The administration of a gas mixture saturated at body temperature raises the isothermic saturation boundary (I.S.B.) all the way up to the mouth, with the following results:

- the elimination of the normal water loss from the respiratory tract, with equivalent heat and water conservation;

- the absence of any positive water gain for the respiratory tract;

- the elimination of thermal and Fickian $\mathrm{P}_{\mathrm{II}_{2} \mathrm{O}}$ gradients which normally underly heat and water exchanges in the upper respiratory tract;

- the replacement of a physiological, dynamic self-compensating mechanism by static artificial conditions;

- the creation of a para-physiological situation which may alter the functions, the integrity and the resistance of the mucous membrane of the upper air passages;

- the addition of the ever-present danger of inadvertently burning the respiratory tract, which can only be prevented by a very close monitoring.

However comforting it may be to observe large amounts of water being evaporated from a heated vaporizer, the result is not water administration to the lungs, but water conservation out of a normal loss. At best, the administration of a gas mixture saturated at body temperature results in the induction of a thermo-hydric steady state, no water being gained or lost by the respiratory tract. 
Finally, it is obvious from our results that the only practical and effective way of inducing a positive water balance in the air passages (either for prophylactic or therapeutic intents) is through the administration of particulate water, i.e. aerosols. The advantages and drawbacks of this practice have been well characterized by others, and are not discussed here. ${ }^{14-22}$

\section{RÉSUMÉ}

Nous avons mesuré, en cours de six expériences d'une durée d'une heure, le bilan hydrique de larbre trachéobronchique dans des conditions de saturation isotherme. Il s'est agi de ventiler l'individu conscient à l'aide d'un respirateur à volume constant, et d'humidifier son air inspiré à saturation à $37^{\circ} \mathrm{C}$. Nous avons absorbé l'humidité de l'expiration au moyen de canisters sériés de $\mathrm{CaCl}_{2}$ anhydre. Nous avons porté une attention particulière à éviter toute condensation en cours de route, ainsi que tout recyclage, si infime soit-il, d'air expiré dans le système inspiratoire et vice versa. Nous y sommes parvenus au moyen d'un système de valves directionnelles pressurisées, et d'une isolation thermique stable à circulation d'eau à $37^{\circ} \mathrm{C}$, de tout le système de ventilation.

Les résultats concordent, et démontrent que dans ces conditions expérimentales, le bilan hydrique se chiffre à zéro. En d'autres termes, tout l'apport hydrique vaporisé par l'humidificateur Cascade ${ }^{\circledR}$ et l'absorbeur géant de chaux sodée se retrouve intégralement dans le système d'absorption situé sur le bras expiratoire.

L'interprétation de ces résultats nous conduit aux conclusions suivantes:

1 - La quantité d'eau cédée par un vaporisateur est un faux indice de l'apport hydrique aux voies respiratoires;

2 - La vaporisation d'eau, à des températures inférieures à $37^{\circ} \mathrm{C}$, ne fournit pas effectivement un apport positif d'eau dans les poumons, mais minimise la déperdition normale d'eau en élevant le niveau de saturation isotherme;

3 - A l'extrême, l'administration de vapeur d'eau à saturation isotherme, à $37^{\circ} \mathrm{C}$, annule les gradients de $\mathrm{P}_{\mathrm{H}_{2} \mathrm{O}}$ et de température qui prévalent normalement aux échanges thermohydriques de l'arbre respiratoire supérieur, de sorte qu'une situation statique artificielle vient remplacer un mécanisme autocompensé d'échanges dynamiques.

La seule façon pratique d'obtenir un bilan hydrique positif dans l'arbre respiratoire demeure l'administration de particules d'eau (aérosols) plutôt que de molécules d'eau (vapeur). Cette méthode a fait l'objet de multiples études, les unes prônant ses avantages, les autres mettant l'accent sur ses dangers; son évaluation globale dépasse les cadres du travail actuel.

\section{REFERENCES}

1. Winslow, C.E.A. \& Herrington, L.P. Temperature and human life. Princeton University Press, Princeton, New Jersey, 1949 (p. 28).

2. Selle, W.A. Body temperature. Charles C. Thomas, Publisher, Springfield, Illinois, 1952 (p. 27).

3. ColE, P. Some aspects of temperature, moisture and heat relationships in the upper respiratory tract. J. Laryng. 67: 449 (1953). 
4. Keele, C.A. \& NeIl, E. Samson Wright's applied physiology. Oxford University Press, 1961 (p. 16).

5. Moore, F.D. Metabolic care of the surgical patient. W.B. Saunders Company, Philadelphia and London, 1959 (p. 17).

6. DÉRY, R. The evolution of heat and moisture in the respiratory tract during anaesthesia with a nonrebreathing system. Can. Anaesth. Soc. J. 20: 296 (1973).

7. GrafF, T.D. \& Benson, D.W. Systemic and pulmonary changes with inhaled humid atmospheres: clinical applications. Anesthesiology. 30: 206 (1969).

8. Physiological responses to hot environments. Medical Research Council Special Report, Series No. 298. p. 164. Her Majesty's Stationery Office, London 1960.

9. Stevens, H.R. Humidification during anaesthesia. International Anesthesiology Clinics, 8: 736 (1970). Little, Brown and Company, Boston.

10. Unpublished data.

11. Déry, R., Pelletier, J., Jacques, A., Clavet, M., \& Houde, J.J. Humidity in anesthesiology: 11. Evolution of heat and moisture in the large carbon dioxide absorbers. Can. Anaes. Soc. J. 14: 205 (1967).

12. SEELX, F.E. Study of changes in temperature and water vapor content of respired air in nasal cavity. Heating, piping and air conditioning. 12:377 (1940).

13. DéRY, R. Humidity in anesthesiology: 1. A modified dew-point hygrometer. Can. Anaes. Soc. J. 14: 104 (1967).

14. Strevens, H.R. \& Albregt, H.E. Assessment of ultrasonic nebulizers. Anesthesiology 27 : $648(1966)$.

15. Tovell, R.M. \& Lrrtze, D.M., Jr. The utilization of fog as the therapeutic agent. Anesthesiology 18: 470 (1957).

16. Cushing, I.E. \& MnLLer, W.F. Considerations in humidification by nebulization. Dis. Chest. 34: 388 (1958).

17. Averx, M.E., Galina, M., \& Nachman, R. Mist Therapy. Pediatrics 39: 160 (1967).

18. Modell, J.H., Giammonia, S.T., \& Davis, J.H. Effect of chronic exposure to ultrasonic aerosols on the lung. Anesthesiology 28: 680 (1967).

19. HERzOG, P. \& NoRLANDER, O.P. Ultrasonic generation of aerosol for the humidification of inspired gases during volume controlled ventilation. Acta Anaesth. Scand. 8: 79 (1964).

20. Cheney, F.W., JR. \& Buther, J. The effects of ultrasonic-produced aerosols on airway resistance in man. Anesthesiology 29: 1099 (1968).

21. Shakoor, M.A., Sabean, J., Wruson, K.M., Hurt, H.H., Jr., \& Graff, T.D. Highdensity water environment by ultrasonic humidification. Pulmonary and systemic effects. Anesth. \& Analg. 47: 638 (1968).

22. Modelt, J.H., Moya, F., \& RuIz, B.C. Blood gas and electrolyte determinations during exposure to ultrasonic nebulized aerosols. Brit. J. Anaesth. 40: 20 (1968). 